\title{
Os saberes privilegiados na formação inicial de professoras da escola básica
}

\author{
The privileged sabers in the initial training of primary school teachers
}

\author{
Marinalva Lopes Ribeiro \\ Pós doutorado em Educação \\ Universidade Estadual de Feira de Santana - UEFS. \\ Feira de Santana, Bahia - Brasil. \\ marinalva_biodanza@hotmail.com \\ Taiara de Lima Silva Sales \\ Mestrado em Educação \\ Universidade Estadual de Feira de Santana - UEFS. \\ Feira de Santana, Bahia - Brasil. \\ tai.limasilva88@gmail.com
}

Resumo: Este estudo é resultado de uma pesquisa qualitativa, cujo objetivo foi compreender como se realiza a formação dos saberes docentes no Curso de Pedagogia de uma universidade pública na Bahia. Autores como Soares (2009) e Pereira (2007), dentre outros, constituíram os sustentáculos às discussões aqui instituídas. Para compor o corpus das apreciações, optou-se pelo uso de epístolas, contando com a colaboração de 06 (seis) professoras egressas do referido curso que atuam em turmas dos anos iniciais do Ensino Fundamental. Para a análise dos dados, utilizou-se a técnica Análise de Conteúdo (BARDIN, 2011). Conclui-se que o curso de Pedagogia, apesar das lacunas, contribuiu para a construção de saberes decisivos para a docência, a saber, conhecimentos específicos, pedagógicos, como também a pesquisa, a postura crítica e reflexiva, a dimensão afetiva e política, evidenciando que as docentes aprenderam a respeitar os alunos e a enxergá-los como sujeitos de direitos, ou seja, reconhecendo que a docência é uma prática política que contribui para a formação de cidadãos críticos.

Palavras-chave: Saberes docentes. Formação inicial. Curso de pedagogia.

Abstract: This study is result of a qualitative research, whose objective was to understand how formation of teaching knowledge is carried out in the Pedagogy Course of a public university in Bahia. Authors such as Soares (2009) and Pereira (2007), among others, formed the basis for discussions established here. In order to compose the corpus of the appraisals, we opted for the use of epistles, with collaboration of 06 (six) teachers graduated from the referred course who worked in classes in the early years of Elementary School. For data analysis, the Content Analysis technique was used (BARDIN, 2011). It is concluded that Pedagogy course, despite the gaps, contributed to construction of decisive knowledge for teaching, namely, specific, pedagogical knowledge, as well as research, critical and reflective posture, the affective and political dimension, showing that teachers have learned to respect students and see them as subjects of rights, that is, recognizing that teaching is a political practice that contributes to formation of critical citizens.

Keywords: Teaching knowledge. Initial formation. Pedagogy course. 


\section{Dialogia}

RIBEIRO, Marinalva Lopes; SALES, Taiara de Lima Silva. Os saberes privilegiados na formação inicial de professoras da escola básica

Introdução

Uma das grandes contribuições do movimento de profissionalização, iniciado nos anos de 1980, foi o reconhecimento de que, no trabalho cotidiano em sala de aula, o professor recorre a saberes e habilidades para resolver determinadas situações na prática da docência. Tais saberes são desenvolvidos tanto no processo de formação inicial, quanto no decurso da formação continuada. Partindo dessa premissa, alguns autores, tais como Shulman (2005), Nóvoa (1995), Schön (1992), Tardif (2014), Libâneo e Pimenta (2002), e Libâneo (2002), veem empenhando-se na ampliação de debates sobre como são construídos tais saberes, fato que tem colaborado para o rompimento da visão tradicional do "fazer docente", na qual, o professor é tido como uma casta de especialista em sua disciplina, como se apenas tal saber fosse suficiente para o processo de ensino-aprendizagem.

Tardif (2014) é um dos principais autores que vem rompendo com a visão clássica de docência. O autor preconiza que o saber docente é múltiplo e pluriorientado por diversos outros saberes originados dos currículos, das disciplinas, do exercício profissional e da experiência pessoal. Segundo o autor, "é impossível compreender a natureza do saber dos professores sem colocá-lo em íntima relação com o que os professores, nos espaços de trabalho cotidiano, são, fazem, pensam e dizem" (TARDIF, 2014, p. 15).

Acompanhando o pensamento de Tardif (2014), o saber profissional é uma amálgama para não dizer concatenação - de diferentes saberes oriundos das mais diversificadas fontes, e que são construídos, relacionados, mobilizados e diligenciados pelas exigências peculiares de cada atividade profissional. Com efeito, Farias (2009, p. 76) afirma que os saberes da experiência,

[...] São saberes produzidos na nossa história escolar, na relação com os professores enquanto discentes, na trajetória profissional nas diversas instituições em que lecionamos, bem como advindos do cotidiano docente. O saber da experiência é oriundo "da" e "pela" prática.

Vale salientar que, sob essa ótica, os saberes da experiência são produzidos no cotidiano do docente, em um processo permanente de reflexão sobre sua prática, sofrendo influência, também, das práticas de outros colegas, além de textos produzidos por diferentes autores. (PIMENTA, 1998) e Tardif (2014, p. 72) apregoam que,

Os saberes experienciais do professor de profissão, longe de serem baseados unicamente no trabalho em sala de aula, decorriam em grande parte de preconcepções do ensino e da aprendizagem herdadas das histórias escolares.

Em vários aspectos, o exercício da profissão docente apreende-se na própria experiência prática, no viver cotidiano do fazer laboral. Tardif (2014), em seus estudos, ressalta o fato de tentarmos entender esses saberes de forma compartimentada, independentes, estanques e de fonte 
única. Pimenta (1998) colabora com a discussão em tela, revelando que são três os saberes necessários à docência: 1) Saberes da experiência, que estão ligados à bagagem experiencial que os professores já trazem quando ingressam no curso de formação docente. 2) Conhecimento entendido não somente enquanto aquisição de informações, levando o/a docente a classificá-las, analisá-las e contextualizá-las. 3) Saberes pedagógicos e, também, saberes didáticos, relacionados à relação professor/aluno e todas as estratégias utilizadas pelos professores na sala de aula.

Anastasiou (2002) eleva para quatro, o número de saberes necessários à docência. Mantendo inalterável na forma e no conteúdo os saberes da experiência e os saberes da área do conhecimento, a autora divide os saberes pedagógicos em: saberes pedagógicos e saberes didáticos. Aqueles são responsáveis por pensar o ensino como uma prática educativa. Estes propõem a articulação entre a teoria da educação e a teoria do ensino.

Colaborando com tal discussão, Cunha (2004) exibe algumas classificações dos saberes necessários ao desenvolvimento da docência. Todavia, o que a diferencia dos outros autores, é que a estudiosa expõe um ponto de vista mais relacionado ao campo da Didática. Assim, considera: os saberes do contexto da prática pedagógica, que estão relacionados com a identificação das teias sociais e culturais que definem os espaços, nos quais os processos de ensinar e aprender ocorrem; os saberes da ambiência da aprendizagem, que estão diretamente ligados à preocupação em despertar a curiosidade dos alunos, ou seja, aprender a questionar, a duvidar, a investigar; os saberes da condição da aula em suas múltiplas possibilidades, ou seja, a criação de um clima propício à aprendizagem dos alunos; os saberes relacionados ao planejamento das atividades de ensino; os saberes relativos à avaliação da aprendizagem. Isto posto, Pimenta (2009, p. 18) defende que um curso de licenciatura

[...] desenvolva nos alunos conhecimentos e habilidades, atitudes e valores que lhes possibilitem permanentemente irem construindo seus saberes-fazeres docentes a partir das necessidades e desafios que o ensino como prática social lhes coloca no cotidiano.

Para tanto, a expectativa é que os cursos de formação inicial em Pedagogia proporcionem ao professor, um contato a priori com os saberes e habilidades necessários ao desenvolvimento da prática a que se propõe, a saber, o exercício da docência. Não obstante, o grande desafio dos cursos de licenciatura é fazer os estudantes "transcenderem de sua condição de discentes, para a condição de futuros docentes, construindo, assim, suas identidades profissionais" (PIMENTA, 2009).

Contribuindo com tal discussão, Paulo Freire (1996) elenca a necessidade de saberes específicos para o exercício da docência. O articulista reforça que tais saberes são "demandados pela prática educativa em si mesma, qualquer que seja a opção política do educador ou educadora” (FREIRE, 1996, p. 21). Na explicitação dos saberes necessários à docência, o autor supracitado 
expõe alguns saberes, competências e conhecimentos que seus pares consideram importantes, como foi exposto anteriormente. Digno de nota é o fato de que, fica explicitada a sua posição em relação à rigorosidade metódica, ao respeito em relação aos saberes e à autonomia dos educandos, à criticidade, à escuta, à reflexão crítica sobre a prática, à autonomia, à indagação, à ética, à estética, à disponibilidade para o diálogo, como elementos fundantes da sua proposta.

Muitos artífices do saber (DAY, 2011; ESPINOSA, 2002; RIBEIRO, 2010; TASSONI, 2000), alinham-se ao pensamento de Freire (1996) na medida em que apresentam, dentre os saberes necessários à docência, aqueles voltados à dimensão afetiva alinhada à dimensão cognitiva. Neste sentido, o professor desenvolve com seus alunos uma relação de parceria, constituindo-se como principal mediador/incentivador, no processo ensino- aprendizagem haja vista que, "a emoção é o primeiro e mais forte vínculo entre os indivíduos" (TASSONI, 2000, p. 22).

Ora, diante da complexidade da docência, será necessário ao professor apropriar-se do conhecimento do conteúdo a ser trabalhado na disciplina e da experiência, como sinaliza Tardif (2014), da competência profissional, do comprometimento e da segurança, como evidencia Freire (1996). Além disso, faz-se necessário, também, no seu processo formativo, a presença de saberes da dimensão afetiva, para que irrompa-se a visão cartesiana de homem na qual corpo e alma, cognição e afetividade estejam dicotomizados. (RIBEIRO, 2010).

Diante da importância dos saberes dos professores da Escola Básica, um questionamento aflora nesta discussão: o Curso de Pedagogia da UEFS possibilitou ou não, a formação dos saberes necessários à prática docente de tais profissionais? A fim de dirimir essa dúvida, realizou-se esta pesquisa, cujo objetivo foi compreender o processo de formação dos saberes docentes no curso aqui analisado. Após essas palavras introdutórias, o artigo explana a metodologia da pesquisa e, por conseguinte, os resultados, que se subdividem em quatro dimensões, as quais são discutidas em diálogo com os autores que ofereceram arcabouço teórico ao estudo. As conclusões estão elencadas a posteriori.

\section{O método da pesquisa}

Para compreender de que forma ocorre o processo de formação dos saberes docentes no Curso de Pedagogia, optou-se por uma pesquisa descritiva de abordagem qualitativa. Na produção das informações, epístolas foram enviadas a dez egressas do ano de 2018 da UEFS que, segundo informações, estavam atuando em escolas públicas como docentes nos anos iniciais do Ensino Fundamental. Na carta-convite as destinatárias foram questionadas sobre os saberes construídos no âmbito acadêmico e as lacunas concernentes à formação no referido curso. Outrossim, 
solicitava resposta por meio de outra missiva que se empregou à título de esteio na construção deste artigo. Em pesquisas educacionais é recorrente o emprego de epístolas na produção de dados. Tal artificio permite que os envolvidos tragam à tona suas ideias no que se refere à sua prática pedagógica. Segundo Lima (2006, p. 140),

É pela linguagem que o professor tem consciência de si mesmo e do seu conhecimento. Dessa maneira, a carta pedagógica tem muitas possibilidades formativas, além de esclarecer conceitos, rever conteúdos, promover questionamentos, em suma, fazer a interlocução entre o formador e os formandos.

Das epístolas enviadas, obteve-se resposta de seis. De posse destas, analisou-se suas escritas, as informações foram cruzadas e destacou-se algumas porções de sentido dignas de análise. Objetivando lograr êxito na empreitada, recorreu-se aos princípios da Análise de Conteúdo (BARDIN, 2011). Ressalta-se aqui todos os cuidados éticos com a pesquisa. Nos envelopes que continham as cartas endereçadas às egressas, continham cópias do Termo de Consentimento Livre e Esclarecido que foram assinados pelas participantes. Ressalva-se que houve o cuidado em preservar os nomes das participantes, que receberam os seguintes codinomes ou pseudônimos: Aline, Jéssica, Mile, Lane, Aline e Gaby.

\section{Resultados e discussão}

Os resultados foram organizados em seis dimensões, as quais serão apresentadas a seguir.

\section{Saberes da trajetória profissional}

É notório que, ao adentrar os cursos de formação inicial, os estudantes trazem consigo saberes de diversas naturezas (sociais, familiares, religiosas e escolares). Portanto, é ingenuidade pensar que somente os cursos de graduação são responsáveis pela construção dos primeiros saberes.

O que comprova tal assertiva é o que nos revela em sua epístola, a professora Gaby:

O Curso de Pedagogia da UEFS me ajudou a esclarecer e ressignificar saberes já construídos em diferentes ambientes sociais, como o familiar e o escolar (desde a educação infantil até o ensino médio) (PROFESSORA GABY, 2018).

Consequentemente, percebemos que um curso de formação inicial deve levar em consideração o sujeito em processo de formação traz consigo saberes, valores e representações que precisam ser valorizados e problematizados, ressignificando-os conforme as demandas da profissão. Neste sentido, Tardif (2014, p. 69) relata que 
[...] tudo leva a crer que os saberes adquiridos durante a trajetória pré-profissional, isto é, quando da socialização primária e, sobretudo, quando da socialização escolar, têm um peso importante na compreensão da natureza dos saberes, do saber-fazer e do saber-ser que serão mobilizados e utilizados em seguida quando da socialização profissional e no próprio exercício do magistério.

Compreende-se, conforme o trecho anterior, que ao ingressarem num curso de formação inicial, os estudantes são possuidores de saberes pessoais para a docência. Esses lhe servirão de base à construção dos saberes específicos e da representação do que é ser e do que faz um professor.

Para Cardoso et al (2012), a construção da representação do ser professor não pode ser limitada somente ao presente, é preciso aceitar as diversas fontes de aquisição dos saberes docentes. Tais fontes acontecem no contexto da vida pessoal, familiar, bem como na trajetória escolar, contribuindo para a constituição da identidade profissional. É nesse sentido que a professora Lane, em sua carta, afirma que o Curso de Pedagogia lhe ajudou na construção da sua identidade docente. Em suas palavras: "Aprendi que ser professor não é transferir conhecimentos, pois nenhum ser é considerado 'tábula rasa”'. Assim, fica evidente que as experiências escolares e, no nosso caso, aquelas construídas no Curso de Pedagogia, são decisivas na construção da identidade docente. Com efeito, como afirma Pimenta (1998), ao ingressarem num curso de formação inicial, os alunos já são possuidores de saberes sobre o que é ser professor, isto porque, eles registram, a partir de suas vivências como alunos, as representações desse ofício, rememorando as imagens dos diversos professores que tiveram ao longo da sua vida escolar. Por consequência, constitui-se um desafio para os cursos de formação docente intervir no processo de transformação da representação que o estudante tem do ser professor, construída anteriormente, para tornar-se professor.

\section{Saberes pedagógicos e didáticos}

O saber pedagógico e didático é outro saber que ficou evidenciado nas escritas das epístolas, conforme evidencia a professora Amanda:

As diversas disciplinas obrigatórias e optativas contribuíram para o desenvolvimento de saberes pedagógicos necessários, tanto para a minha prática pedagógica no âmbito escolar, quanto para o estímulo à pesquisa (AMANDA, 2018).

Esse excerto vai ao encontro de Tardif (2014, p. 37), quando ressalta:

Os saberes pedagógicos apresentam-se como doutrinas ou concepções provenientes de reflexões sobre a prática educativa no sentido amplo do termo, reflexões racionais e normativas que conduzem a sistemas mais ou menos coerentes de representações e de orientação da atividade educativa. 
Pimenta (1998, p. 28), nesse mesmo sentido, pontua que “Os saberes pedagógicos podem colaborar com a prática. Sobretudo, se forem mobilizados a partir dos problemas que a prática coloca, entendendo, pois, a dependência da teoria em relação à prática, pois esta lhe é anterior”. Para corroborar com tal afirmação, ao lermos a carta da professora Jéssica, vimos que ela, em sua prática docente, foi capaz de rememorar discussões das quais participou no Curso de Pedagogia, as quais contribuíram para a elaboração do planejamento escolar e da avaliação da aprendizagem:

Com relação ao planejamento e avaliação, não tive muita dificuldade. Lembro-me de ter tido ótimas e proveitosas discussões na disciplina de avaliação na universidade, que serviram para a prática (PROFESSORA JÉSSICA, 2018).

Nesse caso, a discussão sobre a importância dos saberes pedagógicos e didáticos nos possibilita confirmar que, para ensinar, não basta ao professor apenas adquirir os saberes provenientes da experiência ou decorrentes dos conhecimentos específicos. Portanto, embora apenas as professoras Amanda e Jéssica apresentem tal necessidade, concluímos, com a ajuda dos autores referenciados, que é imprescindível uma base de saberes pedagógicos e didáticos na formação inicial de professores.

\section{Saber disciplinar}

O saber dos conteúdos específicos foi outra dimensão encontrada nas epístolas das egressas. Diretamente relacionado aos componentes curriculares específicos, esse saber deve também ser contemplado no curso de formação inicial, pois é de suma importância que o futuro professor tenha conhecimento sobre a disciplina que irá lecionar. No curso de pedagogia analisado, o saber do conteúdo específico faz parte do "Núcleo de Conteúdos Pedagógicos". Segundo o projeto do curso em vigor à época da pesquisa,

[...] envolve o estudo específico da educação básica para o ensino na Educação Infantil e nos Anos Iniciais do Ensino Fundamental. Os estudos desenvolvidos em torno desse Núcleo focalizarão conhecimentos específicos da educação básica, os conhecimentos didáticos que envolvem a organização do trabalho pedagógico articulando teoria e prática sobre processos de construção do conhecimento pela criança, jovem ou adulto (UEFS, 2002).

Nesse Núcleo, as estudantes - futuras docentes - têm contato com as disciplinas de Ensino da leitura, escrita e produção de textos; Fundamentos e Ensino da História, da Geografia, da Matemática e Ciências Naturais para a Educação Infantil e Anos Iniciais do Ensino Fundamental. Analisando as ementas de tais componentes curriculares, constatamos que o objetivo central desse Núcleo é possibilitar que os estudantes construam os conceitos referentes à cada área. Por exemplo, em Matemática, espera-se que compreendam a história da Matemática, a metodologia da 
Matemática e os pressupostos epistemológicos do conhecimento matemático. Em Leitura, escrita e produção de textos, espera-se que consigam desenvolver práticas de leitura e escrita, bem como sejam capazes de mediar o processo de aprendizagem da leitura e da escrita. No Ensino da História, espera-se o desenvolvimento da habilidade de articular os conceitos de fato, sujeito e tempo, além de criar alternativas para o ensino-aprendizagem da História. No que se refere ao Ensino da Geografia, espera-se que identifiquem as correntes dos pensamentos geográficos, além dos próprios conceitos específicos da Geografia. Por fim, ao cursarem o componente Ensino das Ciências Naturais, espera-se que compreendam o histórico e o objeto de estudo das ciências naturais, bem como quais são os seus pressupostos epistemológicos.

Notamos, todavia, que essa terminologia "Núcleo de Conteúdos Pedagógicos" difere das tipologias trazidas por diversos autores. Assim, Tardif, Lessard e Lahaye (1991), Gauthier (1998), Saviani (1996) e Pimenta (1998) tratam tais saberes como "saberes disciplinares", que correspondem "às diversas áreas do conhecimento, aos saberes que se encontram à disposição da nossa sociedade, tais como se encontram integrados à universidade na forma de disciplinas, no âmbito de faculdades e cursos distintos" (SAVIANI, 1996, p. 220).

Em relação aos saberes disciplinares, destacamos no relato da professora Mile o quanto esses saberes formaram uma base de conhecimentos que lhe ajudaram na prática docente:

\footnotetext{
Deparei-me com discussões sobre técnicas e métodos de ensino, conheci brevemente metodologias de áreas de conhecimento como Matemática, Geografia, Português, Ciências e História, os quais na teoria me dariam base para lecionar em turmas do fundamental I (PROFESSORA MILE, 2018, grifos nossos).
}

Observamos no excerto anterior, no trecho "conheci brevemente" que o saber disciplinar foi visto pela professora Mile de forma insuficiente para lhe dar "base para lecionar em turmas do Fundamental I". Nesse sentido, questionamos se não seria necessário que o Curso de Pedagogia desse maior ênfase às "metodologias de áreas de conhecimento como Matemática, Geografia, Português, Ciências e História”. Essa necessidade formativa encontra respaldo em Libâneo (2011, p. 88), quando afirma: "Isso significa que os professores da Educação Infantil e de $1^{\text {a }}$ a $4^{\text {a }}$ série precisam de um sólido domínio dos conteúdos específicos e das práticas investigativas que lhes são conexas".

Contribuindo com essa discussão, Cunha (2004) defende que é necessário ao professor o domínio profundo do conhecimento da matéria que ensina. Isso não quer dizer que tal profissional adote uma postura prepotente em relação ao conhecimento e o conceba de forma estanque. Pelo contrário, ao ter domínio do conteúdo, o professor consegue desenvolver sua prática baseada na crítica, na dúvida e torna-se estudioso naquilo que lhe diz respeito. Ao fazermos tal afirmação, 
pretendemos esclarecer que "a ferramenta de trabalho do professor é o conhecimento. Por isso, precisa dominá-lo, investigá-lo, ter entendimento sobre o que está trabalhando em sala de aula para que não caia em rotinas esvaziadas e sua prática perca a finalidade” (PINHEIRO; ROMANOWSKI, 2009, p. 237).

\section{A iniciação científica}

Uma das instituições responsáveis pela produção e disseminação do conhecimento é a universidade. Segundo a Lei de Diretrizes e Bases n 4.024/1961, em seu Art. 67, as universidades são responsáveis pela existência de cursos de ensino superior, podendo ser agrupadas em universidades ou não, tendo apoio e cooperação de institutos de pesquisas e centros de treinamentos profissionais.

Essa mesma Lei descreve, no Art. 66, que o ensino superior tem por objetivo a pesquisa, o desenvolvimento das ciências, letras e artes, e a formação de profissionais de nível universitário. $\mathrm{O}$ que diferencia uma universidade de uma faculdade é justamente a tríade: ensino, pesquisa e extensão, na qual ela está imersa. Nesse caso, identifica-se a amplitude do alcance da universidade na formação do profissional, pois a prática da pesquisa propõe elucidar a historicidade dos sujeitos, dos fenômenos sociais e propiciar a produção de conhecimentos e, por outra via, a extensão tem o papel de oferecer, como retorno social, o conhecimento produzido nos meios universitários.

Pimenta (1999) contribui para refletirmos sobre a importância da pesquisa no curso de Pedagogia, quando afirma:

[...] um curso de formação inicial poderá contribuir não apenas colocando à disposição dos alunos as pesquisas sobre a atividade docente escolar (configurando a pesquisa como princípio cognitivo de compreensão da realidade), mas procurando desenvolver com eles pesquisas da realidade escolar, com o objetivo de instrumentalizá-los para a atitude de pesquisa nas suas atividades docentes (PIMENTA, 1999, p. 28).

Nesse sentido, os professores formadores devem desenvolver nos estudantes uma postura investigativa, o que requer dos estudantes uma atividade cognitiva mais complexa que propicia uma aprendizagem duradoura e transferível às novas situações. Todavia, as colaboradoras desta pesquisa não deixaram claro que participaram de práticas em que se articulasse o ensino com a pesquisa na graduação.

Em sua epístola, a professora Gaby relata que desenvolveu várias atividades formativas como: seminários e oficinas. Mas, evidenciou que o espaço consagrado à pesquisa em sua formação se deu na Iniciação Científica. Em suas próprias palavras: 
No decorrer do curso de graduação aproveitei inúmeras oportunidades (discussões e atividades propostas durante disciplinas, seminários e oficinas, experiências em períodos de estágio supervisionado e como bolsista de iniciação científica) nas quais compartilhei um pouco do que sei e aprendi bastante (PROFESSORA GABY, 2018).

Neste sentido, compreendemos que a construção da postura investigativa é essencial por parte dos futuros professores. A pesquisa, portanto, “[...] precisa ser internalizada como atitude cotidiana, não apenas como atividade especial, de gente especial, para momentos e salários especiais" (DEMO, 2011, p. 12).

A Iniciação Científica é um momento que permite ao estudante de graduação o despertar para a pesquisa científica, além de ser uma importante ferramenta para o desenvolvimento da postura ética do profissional. Esse tipo de atividade é um dever de toda instituição de nível superior, tal qual relata a professora Jéssica:

[...] além dos saberes teórico e prático, a iniciação científica me trouxe saberes acerca das metodologias de pesquisa, saberes relacionados à escrita de trabalhos acadêmicos, às dificuldades enfrentadas na pesquisa, apresentação de trabalho, etc. (PROFESSORA JÉSSICA, 2018).

Evidenciamos que o relato desta professora tende a reconhecer a importância da Iniciação Científica para a construção de saberes. A professora Gaby também nos escreveu sobre a importância da pesquisa para a sua formação: "Durante a graduação, produzi artigos e monografia abordando conteúdos importantes da Educação Infantil e séries iniciais do Ensino Fundamental” (PROFESSORA GABY, 2018).

Outra observação que a professora Gaby apontou foi a de que o Curso de Pedagogia lhe ajudou a conscientizar-se sobre a importância da pesquisa, não somente na formação acadêmica, mas também no fazer docente. Além da Iniciação Científica para a sua formação, o curso lhe ajudou a "[...] dar a devida relevância ao ato de pesquisar" (PROFESSORA GABY, 2018). Da mesma maneira, a professora Lane sinaliza a importância da pesquisa para a construção do conhecimento. Em suas palavras, “[...] a construção do conhecimento se dá através do diálogo e da busca, da pesquisa" (PROFESSORA LANE, 2018).

Em síntese, ficou evidente que o formando pode aprender a investigar na universidade em grupos de pesquisa, na construção do seu trabalho de conclusão de curso, mas, também, em todos os componentes curriculares, mediante atividades de questionamento de diversas ideias de diferentes autores, da indagação da realidade, para que aprenda a investigar a sua própria prática e buscar soluções para melhorá-la. 


\section{Saberes da dimensão afetiva}

Diante do atual contexto que envolve o ambiente da sala de aula, é provável que a dimensão cognitiva não seja suficiente para ajudar o professor a lidar com toda essa complexidade. Assim, a aquisição de saberes da dimensão afetiva possibilita ao professor sensibilidade na criação de vínculos com os alunos, facilita a compreensão das necessidades desses aprendizes e permite a abertura sincera para a expressão de sentimentos. Como Paulo Freire (1996) afirma, tal saber nos ajuda na compreensão que estamos lidando com gente.

A professora Lane, ao nos escrever, traz uma importante contribuição para o debate. Segundo ela, um dos saberes que o curso de Pedagogia lhe ajudou a construir foi o afetivo. Em seu relato, evidencia: "Abriu meus horizontes, principalmente, no que se refere a ver o meu próximo, despida de qualquer julgamento pré-estabelecido” (PROFESSORA LANE, 2018). Freire (1996) anuncia que um dos saberes necessários para o desenvolvimento da docência é a possibilidade de o professor se mostrar aberto ao querer bem. Quando a professora Lane nos relata que ampliou seu horizonte na relação com o outro, demonstra estar suscetível às possibilidades de interação e de abertura para conhecer o educando. Ainda que consideremos que a escola tenha o compromisso com o processo de produção do conhecimento, nela também se estabelecem relações afetivas. Com efeito, Almeida (1999, p. 107) assevera que “As relações afetivas se evidenciam, pois a transmissão do conhecimento implica, necessariamente, uma interação entre pessoas. Portanto, na relação professor-aluno, uma relação de pessoa para pessoa, o afeto está presente”.

Nesse sentido, é notório que ao adquirir o saber afetivo, o docente permite-se criar vínculos com os alunos, e a relação que se estabelece entre eles influencia no processo de aprendizagem. Em sua epístola, a professora reflete sobre a importância desse saber para a sua formação. Assim, em seu relato, demarca que para se alcançar uma aprendizagem de qualidade, o aluno precisa "[...] aprender mais por prazer e dominar conhecimentos relativos ao que for estudado no local de ensino" (PROFESSORA GABY, 2018).

A professora Lane descreve em sua epístola: “[...] $\mathrm{Na}$ disciplina de Educação Infantil aprendi a olhar a criança como um ser próprio, um sujeito de direitos" (PROFESSORA LANE, 2018). O relato deixa transparecer que o componente específico Educação Infantil lhe possibilitou a construção de um saber da dimensão afetiva: o respeito ao outro. Durante muito tempo, via-se a criança como a reprodução de um adulto (adulto em miniatura), cujos desejos e direitos não eram respeitados. A partir do desenvolvimento de estudos na área da psicologia, constatou-se que a criança era possuidora de um tempo diferente, tinha necessidades e desejos específicos e que esses deveriam ser respeitados no processo de ensino. Portanto, como Freire ensina, a prática docente é 
permeada por tudo isto: "Afetividade, alegria, capacidade científica, domínio técnico a serviço da mudança” (FREIRE, 1996, p. 143).

\section{Postura crítica e reflexiva}

$\mathrm{Na}$ carta da professora Jéssica, há indícios de que o Curso de Pedagogia lhe ajudou a construir saberes relativos à crítica e à reflexão que considera importantes para a docência. Em suas palavras: "O Curso de Pedagogia da Universidade estudada me ajudou a construir, principalmente, saberes teóricos/reflexivos" (PROFESSORA JÉSSICA, 2018). A partir desse depoimento, podemos inferir que para as professoras investigadas, é de grande importância a construção de uma postura docente reflexiva, o que vai ao encontro de Alarcão (2005, p. 82-83), quando esclarece: “a reflexão sobre o seu ensino é o primeiro passo para quebrar o ato de rotina, possibilitar a análise de opções múltiplas para cada situação e reforçar a sua autonomia face ao pensamento dominante de uma dada realidade".

A professora Lane também enfatiza a importância do professor ser crítico e reflexivo, quando relata: "Aprendi que devemos ser professores críticos e reflexivos diante dos problemas impostos [...]" (PROFESSORA LANE, 2018). Ao afirmar que o Curso de Pedagogia lhe ajudou a construir tal saber, a professora mostra que não assume uma postura passiva diante dos problemas que surgem na sala de aula. Nesse sentido, Alarcão (2005, p. 177) defende que "os professores têm de ser agentes ativos do seu próprio desenvolvimento e do funcionamento das escolas como organização ao serviço do grande projeto social que é a formação dos educandos".

No Projeto do Curso de Pedagogia da UEFS, lócus desta pesquisa, à época deste estudo, está explícita a formação da criticidade: “[...] o fenômeno educativo no processo histórico, dinâmico e diversificado, respondendo criticamente aos desafios que a sociedade lhe coloca". Portanto, observa-se que esse é um saber que as egressas deveriam construir em sua formação inicial.

Schön (1992) é um dos principais estudiosos da prática reflexiva. Para ele, é necessário um novo modelo de formação que se baseie na reflexão da prática. Sua teoria parte de três ideias centrais, a saber: 1) reflexão na ação - está ligada à forma como o professor se mostra capaz de analisar sua prática e como, através das descrições de suas ações, ele demonstra disponibilidade à mudança, podendo adotar novas posturas e elaborar novas estratégias para atuação. 2) A reflexão sobre a ação - acontece quando o professor é capaz de analisar uma situação passada e identificar os caminhos que foram utilizados para resolver determinados problemas. 3) Reflexão sobre a reflexão na ação - possibilita ao professor adotar novas formas de agir, formas de pensar e solucionar problemas. 
Diante do exposto anteriormente, julgamos que é de suma importância aos professores nos cursos de formação inicial desenvolverem a criticidade, a reflexão e a curiosidade para atuarem na sala de aula, tenho em vista que é seu papel formarem cidadãos críticos, capazes de refletir sobre a realidade e transformá-la caso seja necessário. Assim, não conseguimos compreender uma prática na qual a criticidade e a reflexão não estejam presentes.

\section{Palavras conclusivas}

Ficou demonstrado que ao adentrar num curso de formação de professores, as estudantes já trazem consigo representações sobre a docência, sejam elas adquiridas em suas experiências escolares anteriores, sejam angariadas nas relações estabelecidas nos grupos sociais dos quais fazem parte. Assim, o que se espera do curso de formação inicial é que este objetive a construção de saberes necessários ao desenvolvimento da profissão docente e que contribua para que os estudantes de graduação façam a transposição dos saberes constituídos ao longo da formação inicial para aplicação em situações práticas em sala de aula.

Com a análise das epístolas enviadas pelas participantes desta pesquisa, ficou evidenciado que um dos principais saberes construídos pelas egressas do Curso de Pedagogia foi o saber pedagógico, que considera o saber-fazer da prática educativa. Se é importante para a professora estar sensível aos saberes provenientes da experiência, é igualmente importante que essa profissional articule a teoria com a prática e reflita sobre o seu fazer docente, avaliando-o, de modo a perceber qual tem sido o papel da sua prática, ou seja, se está a serviço da manutenção de uma sociedade de classes, ou a favor da humanização das crianças e adolescentes, buscando a sua emancipação.

Além dos saberes já mencionados, pode-se inferir que as egressas do curso de Pedagogia edificaram saberes dos conteúdos específicos que lhe servirão de base para desenvolver a docência, tanto na Educação Infantil, quanto no Ensino Fundamental I. Neste sentido, esta pesquisa concluiu que no curso em estudo, as egressas tiveram as disciplinas de Fundamentos teóricos, ou como consta no projeto do curso "núcleo de conteúdos pedagógicos", no qual se subentende que seja estruturado em torno de componentes curriculares referentes às áreas de fundamentos.

Considerando-se que a legitimidade da universidade se dá também pela articulação entre ensino, pesquisa e extensão, o que se espera do professor é que tal profissional tenha a pesquisa como princípio educativo norteador de suas práticas. A vivência cotidiana do professor em sala de aula está diuturnamente imersa em conflitos de várias ordens (comportamental, afetiva, gestão da classe, convivência com os pares, etc.), motivo pelo qual o profissional precisa adotar a postura de 
pesquisador para analisar as situações que afetam de forma direta a sua prática em sala de aula. $\mathrm{O}$ estudo mostra, nesse sentido, que as professoras investigadas construíram saberes relativos à pesquisa na iniciação científica e no trabalho de conclusão do curso, todavia, o que se esperava é que os saberes relativos à pesquisa fossem desenvolvidos por todos os graduandos, na sala de aula, e não apenas pelos bolsistas de iniciação científica, constituindo-se um saber para o futuro professor investigar a sua prática.

A pesquisa destacou ainda que outro saber fundamental na formação dos pedagogos é a postura crítica e reflexiva diante dos problemas da realidade da sala de aula, de modo a tornaremse agentes ativos do seu próprio desenvolvimento e da transformação da realidade.

Ademais, a pesquisa evidenciou que o curso de formação inicial contribuiu para a construção de outros saberes determinantes para a docência, aqueles relativos à dimensão afetiva e política, quando deixaram transparecer em suas epístolas que aprenderam a respeitar os alunos e a vê-os como sujeitos de direitos, ou seja, reconhecer que a docência é uma prática política que contribui para a formação de consciências.

Por fim, vale destacar que, embora as egressas abordadas por esta pesquisa afirmem que construíram relevantes saberes no Curso de Pedagogia, evidenciaram algumas lacunas, como a dificuldade em se criar conexões coesas entre o campo teórico e a dimensão prática. Talvez seja relevante que haja uma coerência entre o conteúdo programático ensinado pelos cursos de formação e os possíveis revezes que os futuros professores irão encontrar na ambiência da sala de aula, o que pode ocorrer via estágio curricular e outras experiências de interação entre a universidade e a escola básica.

\section{Referências}

ALARCÃO, Isabel (Coord.) Formação reflexiva de professores: estratégias de supervisão. Porto: Porto Editora, 2005.

ALMEIDA, A. R. S. A emoção na sala de aula. Campinas: Papirus, 1999.

ANASTASIOU, Léa das Graças Camargo; ALVES, Leonir Pessate. Processos de ensinagem na universidade: pressupostos para as estratégias de trabalho em aula. Joinville: Univille, 2002.

BARDIN, L. Análise de conteúdo. São Paulo: Edições 70, 2011.

BRASIL. Lei n. 4.024, de 20 de dezembro de 1961. Fixa as diretrizes e bases da educação nacional. Diário Oficial [da] República Federativa do Brasil, Poder Legislativo, Brasília, 27 dez. 1961. p. 11429. Disponível em: http:/ / www.planalto gov.br/ccivil_03/Leis/L4024.htm.

Acesso em: 20 de janeiro de 2016. 


\section{Dialogia}

RIBEIRO, Marinalva Lopes; SALES, Taiara de Lima Silva. Os saberes privilegiados na formação inicial de professoras da escola básica

CARDOSO, Aliana Angioni. Et al. Os saberes profissionais dos professores na perspectiva de tardif e gauthier: contribuições para o campo de pesquisa sobre os saberes docentes no Brasil. IX ANPED Sul, Seminário de pesquisa em educaşão da Região Sul. 2012.

CUNHA, Maira Isabel da. A docência como ação complexa: o papel da didática na formação de professores. In: ROMANOWSKI, J. P. et al. Conbecimento local e conbecimento universal: pesquisa, didática e ação docente. Curitiba: Champgnat, 2004. p. 31-42.

DAY, Cristopher. Pasión por enseñar: la identidad personal y profesional del docente y sus valores. Madrid: Narcea, 2011.

DEMO, Pedro. Educar pela pesquisa. Campinas, SP: Autores Associados, 2011.

ESPINOSA, G. La relation maitre-eleve dans sa dimension affective: un pivot pour une ifférenciation des pratiques pédagogiques enseignantes? In L. Lafortune, P. Mongeau (Dirs.), L’affectivité dans l'apprentissage. Québec: Presses de l’Université du Québec, 2002. p.159-181.

FARIAS, Isabel Maria Sabino de et al. Didática e docência: aprendendo a profissão. Brasília: Liber livro, 2009.

FREIRE, Paulo. Pedagogia da autonomia: saberes necessários à prática educativa. São Paulo: Paz e Terra, 1996.

GAUTHIER, C. Por uma teoria da pedagogia: pesquisas contemporâneas sobre o saber docente. Ijuí: Unijuí, 1998.

LIBÂNEO, José Carlos. Pedagogia e pedagogos, para quê? 5. ed. São Paulo: Cortez, 2002.

LIBÂNEO, José Carlos; PIMENTA, Selma Garrido. Formação dos profissionais da educação: visão crítica e perspectivas de mudança. In: PIMENTA, Selma Garrido. (Org.). Pedagogia e pedagogos: caminhos e perspectivas. São Paulo: Cortez, 2002.

LIBÂNEO, J. C. Didática e trabalho docente: a mediação didática do professor nas aulas. In: LIBÂNEO, J. C.; SUANNO, M. V. R.; LIMONTA, S. V. (Org.). Concepcões e práticas de ensino num mundo em mudança: diferentes olhares para a didática. Goiânia: CEPED/Editora PUC Goiás, 2011.

LIBÂNEO, José Carlos; PIMENTA, Selma Garrido. Formação dos profissionais da educação: visão crítica e perspectivas de mudança. In: PIMENTA, Selma Garrido. (Org.). Pedagogia e Pedagogos: caminhos e perspectivas. São Paulo: Cortez, 2002.

LIMA, Maria Socorro Lucena. Docência e pesquisa em formação de professores: caminhos que se cruzam nas cartas pedagógicas. In: PIMENTA, Selma Garrido et al. Pesquisa em educaşão: alternativas investigativas com objetos complexos. São Paulo: Edições Loyola, 2006. p. 137-148.

PEREIRA, J. E. D. Formação de professores: pesquisa, representação e poder. Belo Horizonte: Autêntica, 2007.

NÓVOA, Antônio (Coord.). Os professores e a sua formação. $2^{\mathrm{a}}$ ed. Lisboa: Dom Quixote, 1995. 


\section{Dialogia}

RIBEIRO, Marinalva Lopes; SALES, Taiara de Lima Silva. Os saberes privilegiados na formação inicial de professoras da escola básica

PIMENTA, Selma Garrido. Formação de professores: saberes da docência e identidade do professor. In: FAZENDA, Ivani (Org). Didática e interdisciplinaridade. Campinas, SP: Papirus, 1998.

PIMENTA, Selma Garrido. Formação de professores: Identidade e saberes da docência. In: PIMENTA, S.G. (Org.) Saberes pedagógicos e atividade docente. São Paulo: Cortez, 1999.

PIMENTA, Selma Garrido. Formação de professores: identidade e saberes da docência. In: PIMENTA, Selma Garrido (Org). Saberes pedagógicos e atividade docente. São Paulo: Cortez, 2009.

PINHEIRO, Geslaine Cristina Grayb; ROMANOWSKI, Joana Paulin. Saberes docentes e a formação inicial do professor para as séries iniciais do ensino fundamental. Anais do IX Congresso nacional de Educação - EDUCERE, III Encontro Sul Brasileiro de Psicopedagogia, 2009. Disponível em: http://www.pucpr.br/eventos/educere/educere2009/anais/pdf/2885_1276.pdf.Acesso em: 23 de novembro de 2016.

RIBEIRO, Marinalva Lopes. A afetividade na relação educativa: estudos de Psicologia, Campinas, p. 403-4012, Jul-Set. 2010.

SAVIANI, Demerval. Os saberes implicados na formação do educador. In: BICUDO, Maria Aparecida; SILVA JUNIOR, Celestino Alves (Orgs.). Formação do educador: dever do Estado, tarefa da Universidade. São Paulo: Unesp, 1996.

SCHÖN, Donald A. Formar professores como profissionais reflexivos. In: NÓVOA, António (Coord.). Os professores e sua formação. Lisboa: Dom Quixote, 1992.

SHULMAN, L. S. Conocimiento y enseñanza: fundamentos de la nueva reforma. Profesorado. Revista de Currículum y formación del profesorado, 9, 2, p. 1-30, 2005. Disponível em:

https://www.ugr.es/ recfpro/rev92ART1.pdf . Acesso em: 01 de janeiro 2017.

SOARES, Sandra Regina. A profissão professor universitário: Reflexões acerca da sua formação. In: CUNHA Maria Isabel da; SOARES, Sandra Regina; RIBEIRO, Marinalva Lopes. Docência universitária: profissionalização e práticas educativas. Feira de Santana: UEFS Editora, 2009.

TARDIF, M. Saberes docentes e formação profissional. Petrópolis: Vozes, 2014.

TARDIF, M.; LESSARD, C.; LAHAYE, L. Esboço de uma problemática do saber docente. Teoria \& Educação, v. 1, n. 4, p. 215-253, 1991.

TASSONI, E. C. M. Afetividade e produção escrita: a mediação do professor em sala de aula. 2000. 246 fl. Dissertação (Mestrado) - Universidade Estadual de Campinas, Campinas, 2000.

Recebido em: 07 abr. 2020/ Aprovado em: 30 jul. 2020

Cite como

(ABNT NBR 6023:2018)

RIBEIRO, Marinalva Lopes; SALES, Taiara de Lima Silva. Os saberes privilegiados na formação inicial de professoras da escola básica. Dialogia, São Paulo, n. 36, p. 502-517, set./dez. 2020. Disponível em: https://doi.org/10.5585/dialogia.n36.17061.

American Psychological Association (APA)

Ribeiro, M. L., \& Sales, T. L. S. (2020, set./dez.). Os saberes privilegiados na formação inicial de professoras da escola básica. Dialogia, São Paulo, n. 36, p. 502-517. https://doi.org/10.5585/dialogia.n36.17061. 